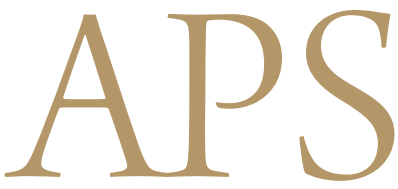

Archives of Plastic Surgery

\title{
Sublabial Autologous Ear Cartilage Grafting for Increasing the Nasolabial Angle
}

\author{
Rajko Toncic, Dinko Toncic \\ Clinic for Cosmetic, Plastic and Reconstructive Surgery Dr Toncic, Zagreb, Croatia
}

Background The loss of nasal tip support is caused by many factors and eventually results in the collapse and eventual dropping of the nasal tip. This reduces the nasolabial (NL) angle and negatively affects respiratory functions and one's appearance.

Methods The aim of this retrospective study, which was conducted on 52 patients, was to present and popularize a simple and effective method for the reconstruction of a weakened columella by inserting an autologous ear cartilage graft using a sublabial approach.

Results Of all the patients, three patients experienced transplant rejection. The period of follow-up observation was one to five years (mean, 27 months). The results were objectively evaluated by measuring the NL angle in standardized photos before and after the procedure at different time intervals over the follow-up period. We observed a significant increase of the NL angle (mean, $20^{\circ}$ ), and found these results to be durable over the long term. Of the 52 patients included in this study observed patients, three were dissatisfied (due to immediate infection and shifting of the strut), 28 were satisfied, and 21 were very satisfied.

Conclusions The surgical method described here is simple and can be learned quickly. It has very good results with few complications, and is our method of choice for complex and serious cases seen in everyday rhinosurgical practice.

Keywords Rhinoplasty / Nasal septum / Cartilage / Esthetics / Nose
Correspondence: Rajko Toncic Clinic for Cosmetic, Plastic and Reconstructive Surgery Dr Toncic, Mlinovi 159 A, 1000, Zagreb, Croatia Tel: $+385-1-461-8888$ Fax: +385-1-463-7801 E-mail: info@toncic.net; rajko@toncic.net

No potential conflict of interest relevant to this article was reported.

\section{INTRODUCTION}

A major problem in cosmetic surgery, if not the largest problem, is the collapse of the tip of the nose, which manifests as reduction of the nasolabial (NL) angle and the loss of nasal tip projection. This process occurs due to the loss of mechanical and structural support of the nasal tip, which can be caused by factors including unfavourable anatomical characteristics of the alar and upper lateral cartilage, the septal cartilage, and its ligaments [1]; ethnically specific anatomical features [2-4]; the aging process $[5,6]$; the influence of gravity; the size of the nose; previous nose or septum surgery [7]; the loss of the upper incisors and upper alveolar ridge atrophy; and trauma and infections of the nose and its supporting structures. Correction of this deformity requires relatively complex operating procedures [8-11].

The columellar strut [12-14] is one of the most important solutions to this difficult problem in both functional and aesthetic rhinoplasty. The most logical solution to the problem of a distorted nose tip lies in solid tissue implantation, which, in this case, is made out of the patient's own cartilage.

There are not many ways to place the strut in the columella $[12,15]$. Today, the strut is usually placed using the open rhino- 
plasty method [14], but this technique does not adequately address how to perform operations in which only the nose tip needs to be raised, while simultaneously preserving the integrity of the nose. Therefore, we developed a method that is superior to previous methods in terms of the ease of strut placement.

Our method involves a sublabial approach to the anterior nasal spine, in which a pocket is made between the medial crura of the alar cartilages, in front of the caudal edge of the septum $[12,16$, 17]. This pocket is used to insert the cartilage.

Every surgical procedure was preceded by a detailed nasal examination and analysis of the relationship of the soft tissues of the face and nose, with a focus on the profile [18]; an assessment of whether surgery was previously performed on the nose; visualization of the NL angle; rhinoscopic examination; and palpation and use of pressure on the nose tip, which provides insight regarding the degree of nose tip collapse.

\section{METHODS}

\section{Other methods}

Many other methods have been developed for raising the nasal tip. To a greater or lesser extent, the following techniques are standard procedures in the rhinosurgical armamentarium: the umbrella or T-graft developed by Peck and Heiden [19], medialization of the medial crura of the alar cartilage, the premaxillary graft, the shield-tip graft developed by Sheen and Sheen [20], the lateral crural steal technique $[8,10,14]$, medial crural-caudal

\section{Fig. 1. A folded strut in situ}

Intraoperative view of a folded strut with mattress sutures ready for insertion.

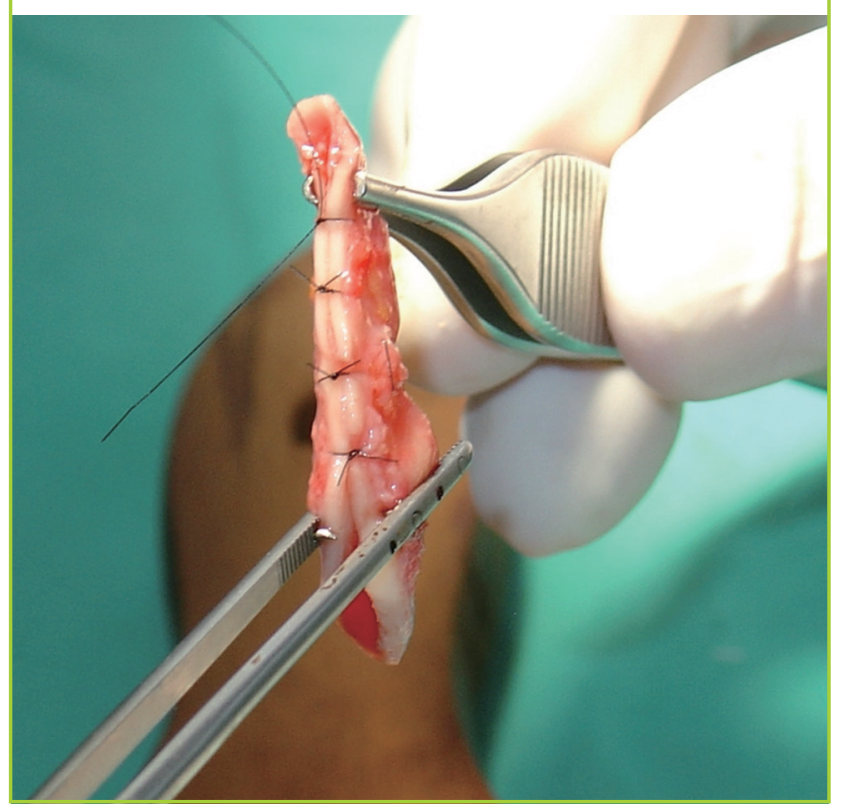

septal imbrication, the tongue-in-groove technique [10,17,21], the contoured auricular projection graft developed by Porter et al. [22] as an alternative to the onlay graft developed by Sheen, and various other types of nasal tip grafts $[7,14,23]$.

\section{Surgical techniques}

Over the past 15 years, we have developed a surgical method for raising the nasal tip in cases where the NL angle is significantly lower (by more than $10^{\circ}$ ) than to the standard $90^{\circ}$, and where the nasal tip shows drooping.

\section{Preparation and insertion of cartilage}

We use the retroauricular approach to remove a relatively large piece of cartilage (approximately $1.5 \mathrm{~cm} \times 3 \mathrm{~cm}$ ) from the cavum conchae area and fold it in the middle by applying an incomplete longitudinal cut. The free edges of the graft are stitched with nonabsorbable 6-0 sutures. In this manner, we obtain a solid, massive graft that will resist resorptive changes and at the same time be statically superior.

If a strut made this way is bent to one side, it is corrected with appropriate 6-0 nonabsorbable mattress sutures (e.g., Ethilon).

The dimensions of the strut are $2.5-3.0 \mathrm{~cm}$ in length and $0.5-$ $0.7 \mathrm{~cm}$ in width (Figs. 1, 2).

Before the implant is inserted, a pocket is formed using a sublabial approach and a small $1-\mathrm{cm}$ horizontal incision is made in the gingival sulcus of the frenulum. Further access to the anterior nasal spine is made with scissors, and a pocket is made behind and between the medial crura of the alar cartilages. The pocket should not be too wide, it should not extend too far towards the caudal part of the septum, and it must not extend under the skin of the nasal tip (Fig. 3).

\section{Fig. 2. Preparation of a folded strut}

A sketch of the cartilage graft used in this technique. (A) Cartilage graft with a longitudinal incision. (B) Side view of the folded strut ready for insertion. (C) Frontal view of the folded strut with mattress sutures ready for insertion.

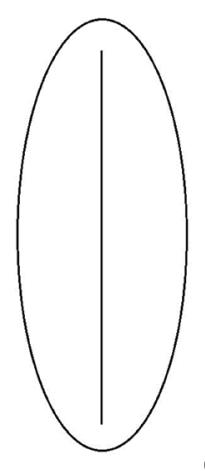

(A)
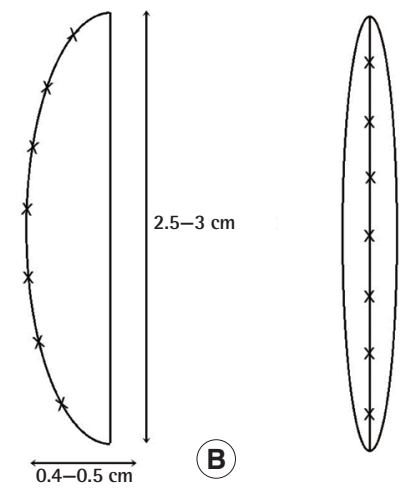


\section{Placement and insertion of the implant}

The columella is held with the thumb and forefinger of the left hand while the implant is taken with Adson-Braun forceps and, as gently as possible, inserted into the pocket, making sure that it does not extend under the skin of the tip (Fig. 4). When the implant is placed, the distal part of the implant is located directly in front of the anterior nasal spine on the premaxilla, and it is then fixed with absorbable sutures (e.g., Vicryl 4-0). During the fixation of the implant, it is necessary to verify that the implant is well centred and positioned in the middle of the columella. Sometimes, if under relatively strong tension, it must be shortened. Before closing the incisional wound, the pocket is rinsed with an antibiotic (gentamicin).

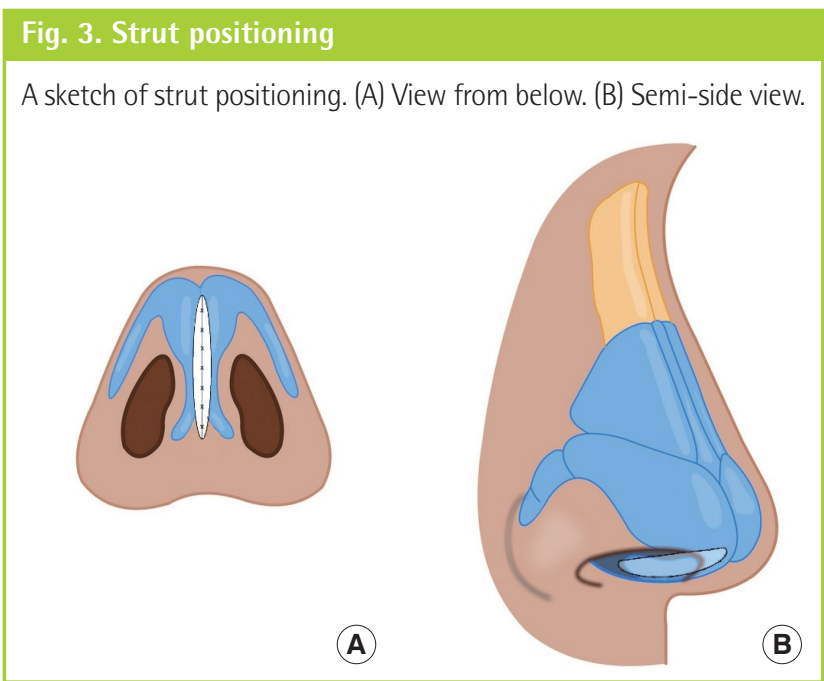

Insertion of the cartilage implant is a highly effective and simple surgical method. The procedure takes 40 minutes, is performed under local anaesthetics with sedation, and has a low rate of complications and failure.

It can be performed independently as a single surgical procedure for raising the nasal tip or as part of a complete rhinoplasty. It is equally effective in both primary and secondary rhinoplasty.

Primary rhinoplasty involves treating a retracted columella, a hanging and drooping nasal tip, and reduced projection of the nasal tip. In secondary rhinoplasty, this method is used on a retracted columella, a collapsed nasal tip caused by the over-resection of supporting structures, or after septoplasty in which the nasal tip has dropped due to distal over-resection and the resection of other parts of the cartilaginous septum. This method can also be successfully applied in cases of septal perforation stemming from various causes and resulting in drooping of the nasal tip.

The surgical technique described above allows stabilization of the nasal tip, which becomes firm to the touch and no longer droops. The volume and projection of the columella are increased, while the NL angle is significantly increased to the point of no longer being acute. The specific outcomes vary from case to case (Figs. 5-7).

\section{Definition of the nasolabial angle}

The NL angle is the angle between the lower edge of the columella (the line that connects the lower edge of the columella to the subnasal point) and the upper lip (a line tangent to the upper lip and subnasal point). This angle is ideally $100^{\circ}-105^{\circ}$ in

\section{Fig. 4. Intraoperative strut insertion}

Insertion of the folded strut into the pocket using Adson-Braun forceps and scissors, ensuring that it does not extend under the skin of the tip. (A) The scissors hold the pocket open and lead the strut into the correct position. (B) Final adjustment of the strut into the desired position using Adson-Braun forceps.
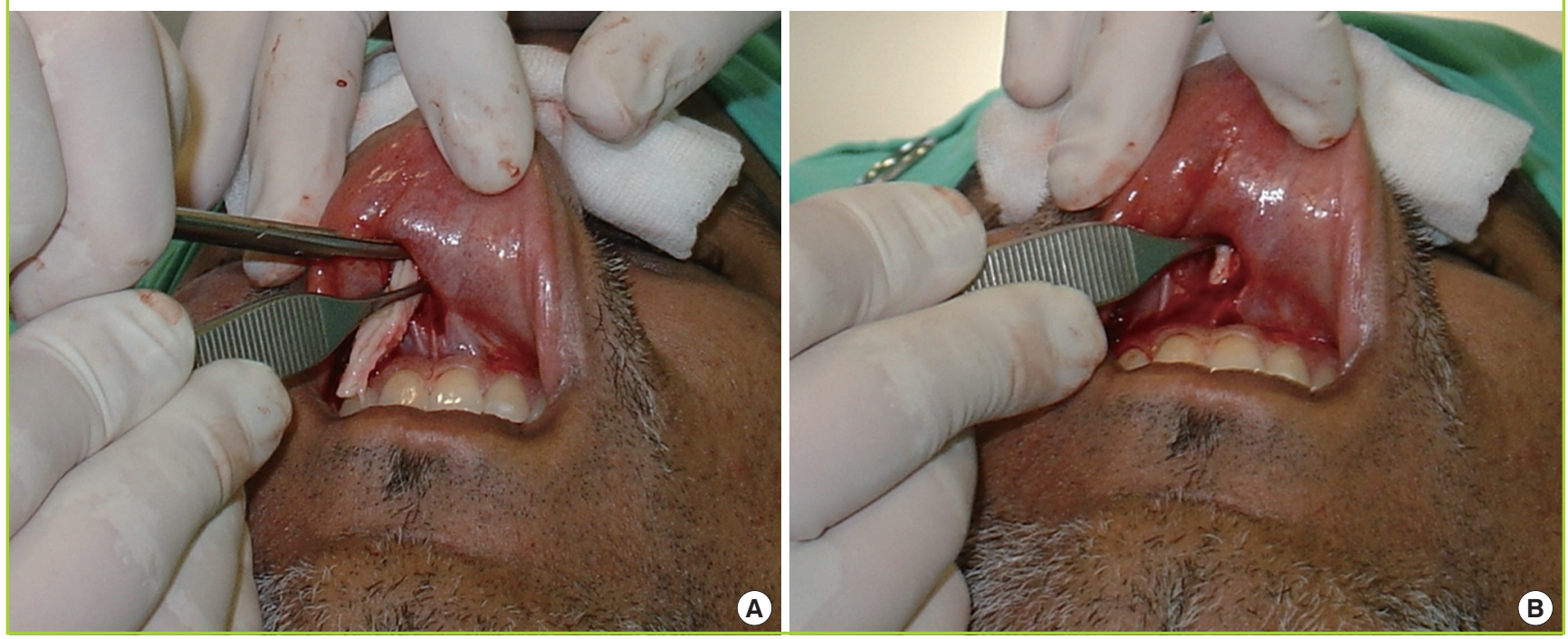
women and $95^{\circ}-100^{\circ}$ in $\operatorname{men}[24,25]$.

\section{Patients and methods}

In this retrospective study, we analysed the photographs of 52 patients treated in our private practice from 2006 to 2010. Fol- low-up observations were made over one to five years, and standardized photographs were taken before and after the placement of a NL strut.

We measured the increase in the NL angle after surgery. Of the patients included in this study, 33 were female and 19 were male.

\section{Fig. 5. Increased nasolabial angle in a male patient}

Increase of the nasolabial angle and nasal tip projection via strut insertion after severe collapse of the nasal tip due to an athletic injury (boxing) in a male patient. (A) Preoperative nasolabial angle, $79^{\circ}$. (B) Postoperative nasolabial angle, $108^{\circ}$.
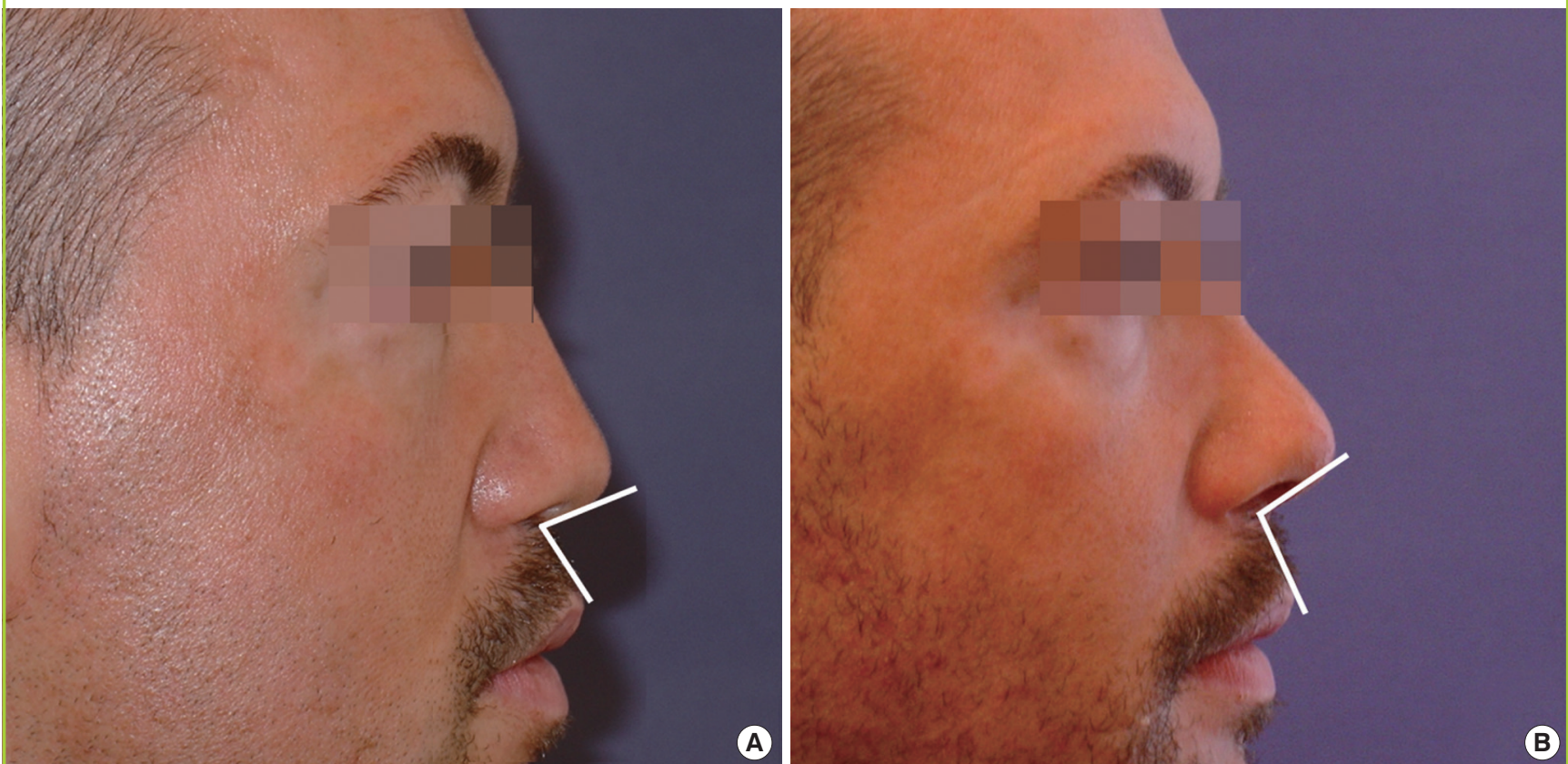

\section{Fig. 6. Increased nasolabial angle in a female patient}

A female patient with a large nose and a collapsed nasal tip due to the lack of septal cartilage support. The nasolabial angle was measured before and after strut insertion and rhinoplasty using a closed approach. (A) Preoperative nasolabial angle, $108^{\circ}$. (B) Postoperative nasolabial angle, $120^{\circ}$.
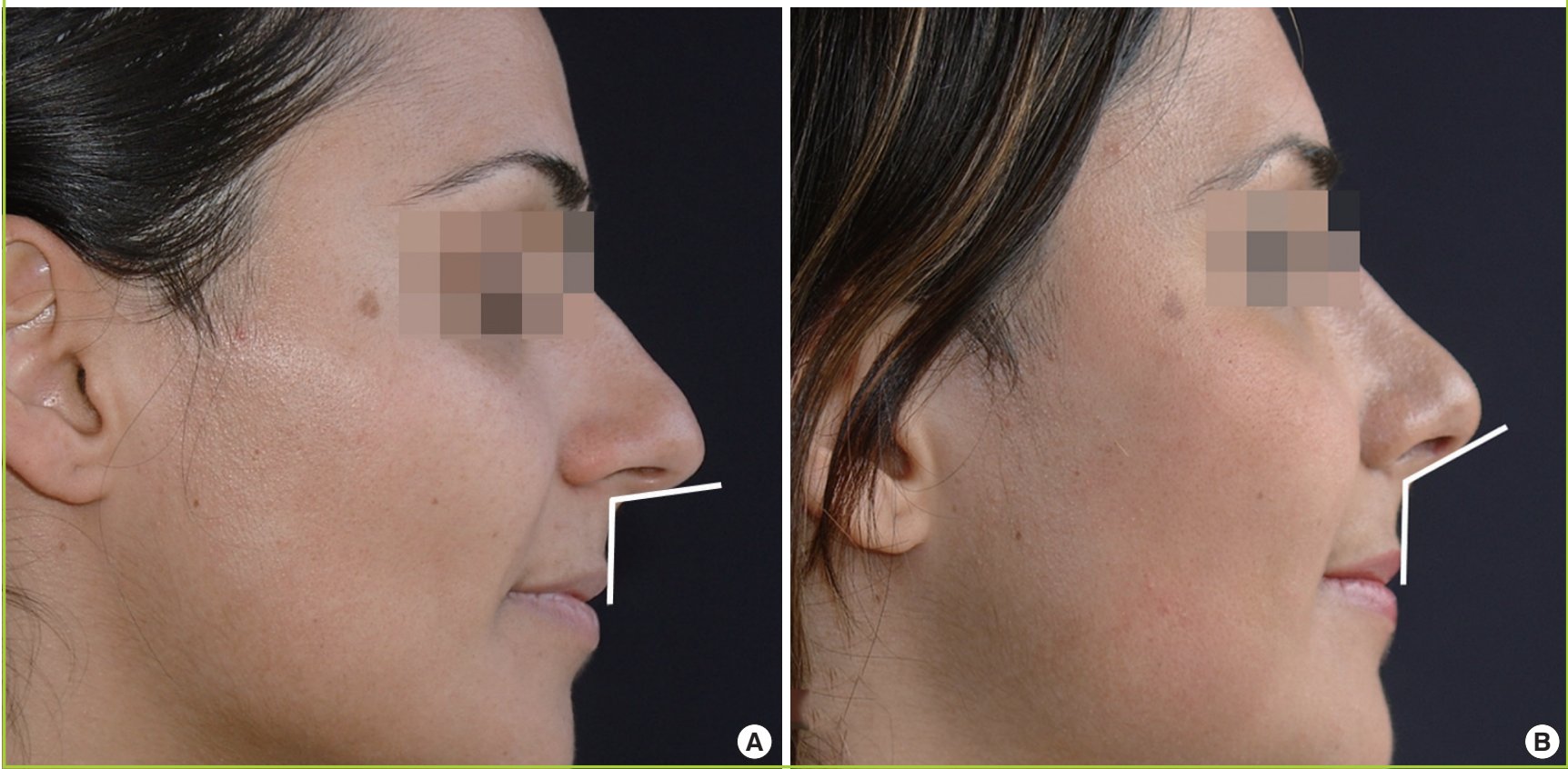


\section{Fig. 7. A patient before and after cartilage strut insertion}

A male patient with a large nose and a collapsed nasal tip due to the lack of septal cartilage support. The nasolabial angle was measured before
and after strut insertion and rhinoplasty using a closed approach. (A) Preoperative nasolabial angle, $64^{\circ}$. (B) Postoperative nasolabial angle, $93^{\circ}$.
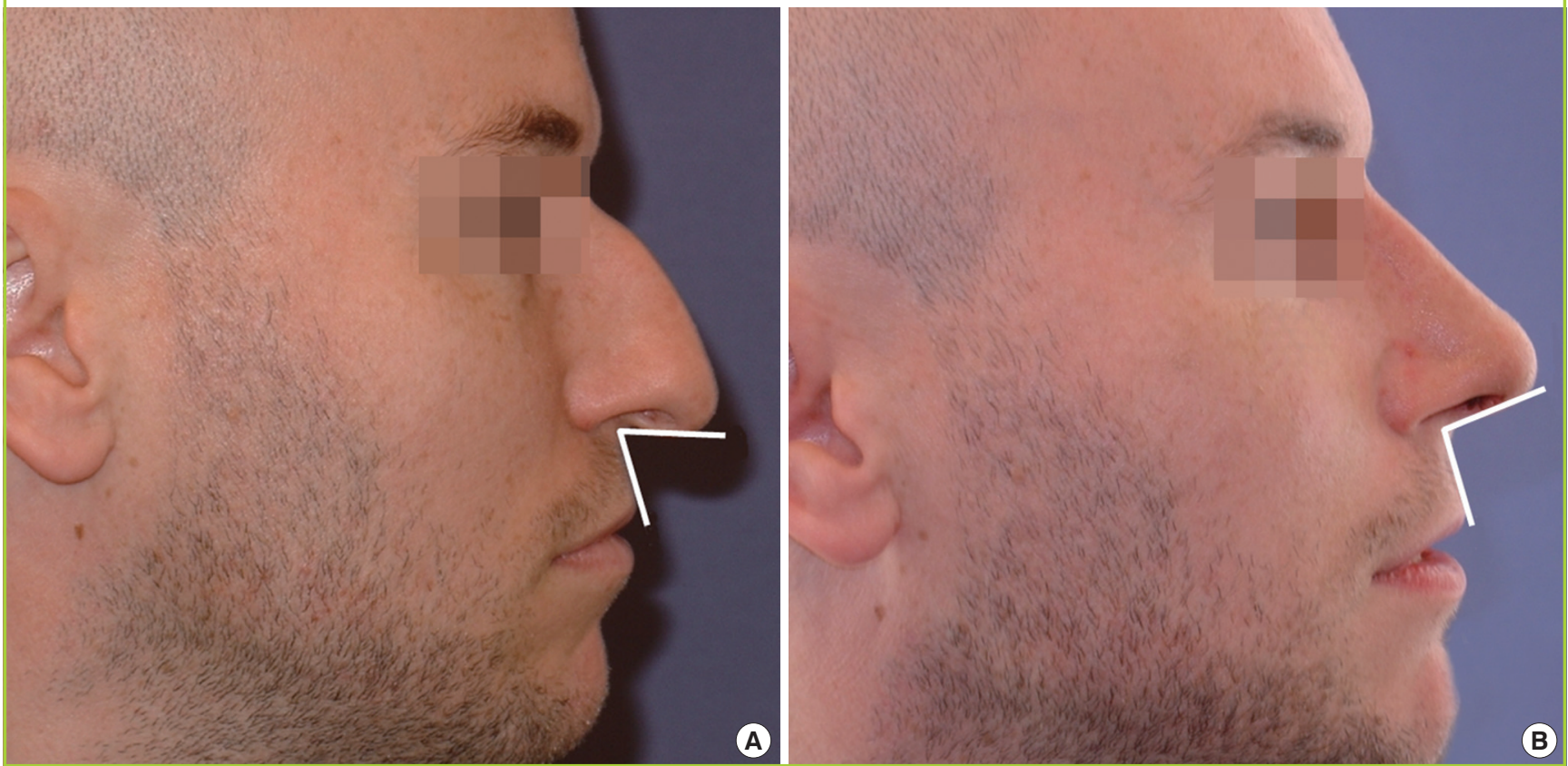

\section{Table 1. Changes in the nasolabial angle in male patients}

\begin{tabular}{|lc|}
\hline Sample of $\mathbf{1 9}$ male patients & Average values $\left.\mathbf{(}^{\circ}\right)$ \\
\hline Average nasolabial angle before surgery & 84.36 \\
Average nasolabial angle after surgery & 103.84 \\
Average increase of the nasolabial angle & 19.48 \\
\hline Significant changes in the nasolabial angle were observed after surgery in the \\
sample of 19 male patients. \\
\hline
\end{tabular}

The mean age of the women was 37 years, while the average age of the men was 38 years. The follow-up period ranged from one to five years (mean, 27 months).

Informed consent was obtained from all patients, as well as authorization for photographs, according to the guidelines of the American Society of Plastic Surgeons.

\section{RESULTS}

Statistical analysis was performed using Microsoft Office Excel 2007, Microsoft Corporation, Redmond, WA, USA; Minitab, Minitab Inc., State College, PA, USA; SPSS ver. 21.0., IBM Co., Armonk, NY, USA.

\section{Data before surgery}

The average value of the NL angle in the 19 male patients before surgery was $84.36^{\circ}$ (Table 1), compared to $84.64^{\circ}$ in the $33 \mathrm{fe}$ male patients (Table 2). No statistical analysis was performed to
Table 2. Changes in the nasolabial angle in female patients

\begin{tabular}{lc}
\hline Sample of $\mathbf{3 3}$ female patients & Average change $\mathbf{(}^{\circ}$ ) \\
\hline $\begin{array}{l}\text { Average number of degrees of the nasolabial angle } \\
\text { before surgery }\end{array}$ & 84.64 \\
$\begin{array}{l}\text { Average number of degrees of the nasolabial angle } \\
\text { after surgery }\end{array}$ & 103.12 \\
\begin{tabular}{l} 
Average increase of the nasolabial angle in degrees \\
\hline
\end{tabular} & 18.48 \\
\hline
\end{tabular}

Significant changes in the nasolabial angle were observed after surgery in the sample of female patients.

compare these figures, because they were essentially equivalent clinically.

\section{Data after surgery}

The average values of the NL angle in the male patients after surgical intervention was $103.84^{\circ}$ (Table 1), compared to $103.12^{\circ}$ in the female patients (Table 2). The average increase of the NL angle after surgery was $19.48^{\circ}$ for the male patients (Table 1 ) and $18.48^{\circ}$ for the female patients (Table 2).

If the three patients who experienced postsurgical complications in the form of infections and graft displacement are excluded, we attained an $20^{\circ}$ increase of the NL angle on average in the entire study population of 49 patients ( 31 women and $18 \mathrm{men}$ ) (Table 3).

Statistical analysis of the all patients showed a significant increase in the NL angle $(\mathrm{P}<0.0001)$ (Table 4$)$. 


\section{Table 3. Increases in the nasolabial angle}

\begin{tabular}{lc}
\hline $\begin{array}{l}\text { Sample of } \mathbf{4 9} \text { patients } \\
\text { (31 women and } \mathbf{1 8} \text { men) }\end{array}$ & Average values $\left(^{\circ}\right)$ \\
\hline Average nasolabial angle before surgery & 84.60 \\
Average nasolabial angle after surgery & 104.60 \\
Average increase of the nasolabial angle & 20.00 \\
\hline
\end{tabular}

The average increase of the nasolabial angle $\left(^{\circ}\right)$ after surgery, after three patients with serious complications were excluded.

\section{Table 4. Two-tailed t-test}

\begin{tabular}{lcc}
\hline Surgery & Nasolabial angle $\left({ }^{\circ}\right)$, mean \pm SD & P-value \\
\hline Before & $84.53 \pm 9.02$ & $<0.0001$ \\
After & $103.38 \pm 10.57$ & \\
\hline
\end{tabular}

Effects of the columellar strut insertion method on the nasolabial angle. P-values $<0.01$ were interpreted as indicating statistical significance. $\mathrm{SD}$, standard deviation.

In follow-up examinations conducted in the first 26 months after surgery, the average increase of the NL angle was $19.72^{\circ}$, while in follow-up examinations conducted more than 26 months after the operation, the average increase of the NL angle was $18.03^{\circ}$. These results clearly indicate that our augmentation of the NL angle was stable over time.

\section{Patient satisfaction}

In cosmetic surgery, patient satisfaction with the outcomes of a procedure is a very important factor. Although satisfaction is subjective and based on an individual's evaluation of a surgical result, we objectively evaluated outcomes by measuring and comparing the $\mathrm{NL}$ angle before and after the surgical procedure. In cosmetic surgery, a range of methods are used to evaluate patient satisfaction. In this study, we used a simple three-option scale to evaluate patient satisfaction after aesthetic nose correction. Of the 52 patients, three were dissatisfied (due to immediate infection and shifting of the strut), 28 were pleased, and 21 were very pleased with the results (Fig. 8).

\section{DISCUSSION}

Due to the complex and variable anatomical and anthropometrical relations in the area of the upper lip, premaxilla, anterior nasal spine, columella, and nasal base [18], establishing exact criteria for defining a droopy nasal tip is exceptionally difficult. Therefore, for this research, we focused solely on measuring changes in NL angles before and after surgical procedures in which our novel method was applied.

The use of an autologous cartilaginous double-folded implant as a strut has proven to be ideal for the aforementioned indica-

\section{Fig. 8. Patient satisfaction $(n=52)$}

Patient satisfaction after their postoperative check-up. US, unsatisfied; VS, very satisfied; $S$, satisfied.

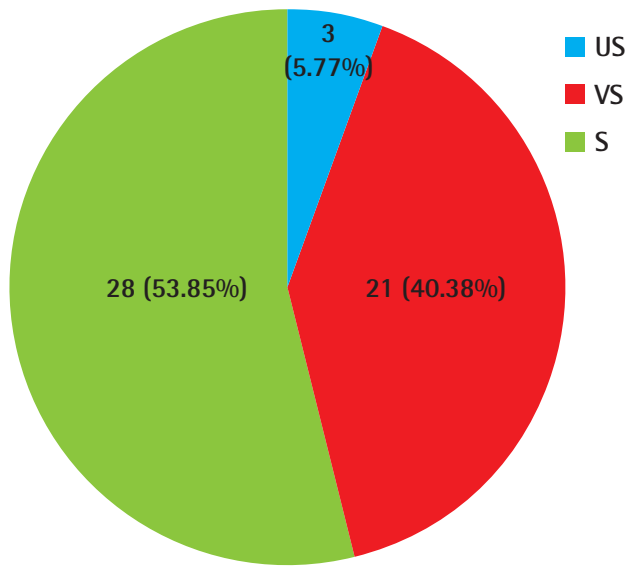

tions. Septal cartilage is too thin, inadequate, or not solid enough for achieving the above results.

We used a sublabial approach in these patients because, after years of experience, we have found that graft insertion through a transfixion incision leads to a higher incidence of infection and transplant rejection. Using sublabial access, we experienced only two cases of infection and one case of graft shifting. These patients underwent surgery at the beginning of the observed series, and as our techniques improved (flushing of the implantation pocket with antibiotics, faster implantation, and precise closing of the incision), we no longer had any cases with major complications.

Moreover, we realized that the transplant must be placed into the pocket without physical contact with the nasal cavity, because the nasal cavity is always contaminated. This led us to perform this surgery as a separate surgical procedure in most cases.

\section{REFERENCES}

1. Beekhuis GJ, Colton JJ. Nasal tip support. Arch Otolaryngol Head Neck Surg 1986;112:726-8.

2. Farkas LG, Hreczko TA, Deutsch CK. Objective assessment of standard nostril types: a morphometric study. Ann Plast Surg 1983;11:381-9.

3. Baker HL. Anatomical and profile analysis of the female black American nose. J Natl Med Assoc 1989;81:1169-75.

4. Porter JP, Olson KL. Analysis of the African American female nose. Plast Reconstr Surg 2003;111:620-8.

5. Krmpotic-Nemanic J, Kostovic I, Rudan P, et al. Morphological and histological changes responsible for the droop of the nasal tip in advanced age. Acta Otolaryngol 1971;71: 
278-81.

6. Rohrich RJ, Hollier LH Jr, Janis JE, et al. Rhinoplasty with advancing age. Plast Reconstr Surg 2004;114:1936-44.

7. Petroff MA, McCollough EG, Hom D, et al. Nasal tip projection. Quantitative changes following rhinoplasty. Arch Otolaryngol Head Neck Surg 1991;117:783-8.

8. Ghazipour A, Ghadakzadeh S, Karimian N. The comparison between two different combinations of alar cartilagemodifying techniques: is lateral crural steal the choice? Eur Arch Otorhinolaryngol 2009;266:391-5.

9. Benlier E, Top H, Aygit AC. Management of the long nose: review of techniques for nasal tip supporting structures. Aesthetic Plast Surg 2006;30:159-68.

10. Foda HM. Management of the droopy tip: a comparison of three alar cartilage-modifying techniques. Plast Reconstr Surg 2003;112:1408-17.

11. Foda HM, Kridel RW. Lateral crural steal and lateral crural overlay: an objective evaluation. Arch Otolaryngol Head Neck Surg 1999; 125:1365-70.

12. Cohen S, Ad-El D, Yaniv E, et al. Sublabial approach for columellar reconstruction in corrective rhinoplasty. J Plast Reconstr Aesthet Surg 2009;62:1446-52.

13. Pastorek NJ, Bustillo A, Murphy MR, et al. The extended columellar strut-tip graft. Arch Facial Plast Surg 2005; 7:176-84.

14. Rohrich RJ, Liu JH. The dorsal columellar strut: innovative use of dorsal hump removal for a columellar strut. Aesthet Surg J 2010;30:30-5.

15. Bloom DC, Cupp CL. The percutaneous columellar strut.
Am J Rhinol 2003; 17:357-61.

16. Webster RC, Hopping SB, Hall B, et al. Intraoral insertion of grafts to project the nasal tip. Arch Otolaryngol 1982;108: 187-93.

17. Rees TD, Wood-Smith D. Cosmetic facial surgery. Philadelphia: Saunders; 1973.

18. Anic Milosevic S, Lapter Varga M, Slaj M. Mogucnosti analize mekih tkiva u ortodontskoj dijagnostici. Acta Stomatol Croat 2007;41:251-9.

19. Peck GC, Heiden C. Nasenplastik: ein operationsatlas. New York: Thieme; 1986.

20. Sheen JH, Sheen AP. Aesthetic rhinoplasty. St. Louis: Mosby; 1987.

21. Kridel RW, Scott BA, Foda HM. The tongue-in-groove technique in septorhinoplasty: a 10-year experience. Arch Facial Plast Surg 1999; 1:246-56.

22. Porter JP, Tardy ME Jr, Cheng J. The contoured auricular projection graft for nasal tip projection. Arch Facial Plast Surg 1999; 1:312-5.

23. Echeverry A, Carvajal J, Medina E. Alternative technique for tip support in secondary rhinoplasty. Aesthet Surg J 2006;26: 662-8.

24. Rorich RJ, Janis JE. Clinical decision-making in rhinoplasty. In: Nahai F, editor. The art of aesthetic surgery: principles \& techniques. St. Louis, Mo.: Quality Medical Pub.; 2005. p.1527-74.

25. Farkas LG, Kolar JC, Munro IR. Geography of the nose: a morphometric study. Aesthetic Plast Surg 1986;10:191-223. 